\title{
Designing an Adaptive Distributed Tutoring System based on Students' Learning Style and Collaborative Learning using Intelligent Agents
}

\author{
T.T. Sampathkumar \\ Tata Consultancy Services \\ Chennai
}

\author{
R. Gowri \\ Pondicherry
}

\author{
Venkateswaran V \\ Assistant Professor \\ Pondicherry
}

\begin{abstract}
This study developed an adaptive distributed tutoring system targeting on students' learning style and collaborative learning. The system is composed of intelligent agents which plays a definite role in making the system adaptive using the association rule mining and fuzzy $\mathrm{C}$-means clustering. This agent oriented system is modeled using Tropos for a consistent development. The system is composed of a student model, a tutor model and a system model. The adaptation is derived into three levels of adaptation namely user level adaptation, user interface level adaptation and system level adaptation. In the user level adaptation, the system would adaptively recommend contents with variety of contents based on the individual learning behavior and overall performance of the students. The user interface level adaptation would allow the user to personalize the user-interface based on his/her own likeliness. Our system would persist the personalization in the user interface and whenever user logs in to the system, the personalized user-interface is presented. The system level adaptation would store/replicate contents in the distributed environment which is based on the current system disk space and memory available in the system. A total of 144 students had been taken in our study with Java as the course. The experimental result reveals various styles of the user and how the individual performance varies from the group. The results also provide an evidence of the system could increase learning factor of the students.
\end{abstract}

\section{Keywords}

Agents, Tutoring System, Intelligent Learning System, Tropos, Extension of Tropos

\section{INTRODUCTION}

Due to the tremendous exploration of the web, the students are provided with versatile contents ranging from the presentations to video materials. But the web based learning also has its limitations, since the students are not provided with proper guidelines in the learning activity. In today's life, the concept of personalization has its role in personalized music, personalized shopping etc.

People have different styles of learning, cognitive skills, likeliness that can influence the contents that is provided by the system. Any learning system should provide a simulating environment such that the student can learn as much as possible. The system must be capable of capturing the learning styles, cognitive skills and likeliness of the learners to provide an adaptive tutoring system. The learning system must create an ample interest in using the system and finally it should create an adroit after completing the specific course.
Adaptive learning may be defined as "the process of generating a unique learning experience for each learner based on the learner's personality, interests and performance in order to achieve goals such as learner academic improvement, learner satisfaction, effective learning process and so forth" [7].

Adaptive Hypermedia Systems (AHS) are systems that use user and concept models to provide a personalized version of the information for the end user. Adaptive Educational Hypermedia Systems (AEHS) are those that create a unique learning experience for each learner based on learner's knowledge-base, goals, learning style and so forth [9].

Only few studies have been made which connects the psychological aspects of the students which impact the learning behavior of the students 6]. Hence building a learning system considering the psychological aspects would be a key concern. Hence the need of providing adaptive materials in the learning environment paves the way for the personalized environment. The course structure and the learning practices of the students are the important issues in developing such learning or tutoring system [1].

Good programming skills are one of the core competencies which are expected in the field of computer science and engineering. Hence our work would concentrate on improvising the programming competencies of the students by providing the appropriate information and contents.

The main motto of work is to provide personalized tutoring to the learners. The Tutoring system has to handle huge amount of data in order to provide adaptive contents. This includes audio, video, open source tools, text and internet. And also there is a need to store and access such distributed contents with minimum system performance and network usage. Most of the Agent based Tutoring systems [7] [8] [9] [29] [30] find difficulty of handling and managing contents that leads the system to an undesired state.

Because of the adaptive characteristics of intelligent agents, researchers have tried to apply the capability of agents in the world of intelligent tutoring systems. Multi-agent systems (MAS) bring several advantages to the implementation of intelligent tutoring systems since they deal well with distribution, cooperation, and integration of computer software components. Hence in this work the Agent based Distributed Tutoring system is considered which emphasize on distribution of resources and accessing the resources in a secured manner.

Tropos [17] [18] [19] [20] has been used for modeling the requirements of the agent oriented system by the goals and tasks in which the system's requirements are adaptive in 
nature. We have used Tropos to develop the agent based intelligent tutoring system.

\section{LITERATURE SURVEY}

The need of the adaptive systems has been increasing every day. Hence e-learning systems must be capable of providing adaptive contents to the user. Many students fail to learn due to the full freedom in many learning systems. There is also a lack of guidance provided to the students when they deviate from the normal learning path. The individual differences in the students learning play a vital role in developing such adaptive learning systems [2]. People generally have different cognitive styles and different capabilities of learning [2]

Hence any while building any such adaptive systems we must address the different styles of learning. The student's interaction with the system could impact the learning behavior. Hence obtrusively asking the students might not motivate the students to use the system for a longer time [6]

Many multi-agent systems have been used in the development of such adaptive systems using SCROM and web-ontology [10]. In [11] discuss about the impact of the learner's attributes such as gender, ethnicity and task specific attributes.

The concept of fuzzy has been used in various areas especially it is used in building and determining the student model in the intelligent tutoring system [14] where it is used to predict the behavior of the students and to classify the materials .

Since only few systems have applied software engineering approach for development of such agent based systems. Tropos is used to model the agent based systems, in this work the agent based adaptive tutoring system is modeled using Tropos methodology. The components of the Tropos methodology are discussed in the section.

\section{PILOT SURVEY}

The pilot survey in prior to the development of adaptive tutoring system helps to identify the needs of the students and the tutoring methodology. In this survey we have a set of questionnaires which targets the students and teachers. From this survey, we incurred that the students have a greater preference towards the multimedia contents such as audio and video based contents rather than a formal method of teaching. But most of the students are not provided with the appropriate contents; hence it would make the students to spend time in identifying the worthy contents rather than learning from those contents. Hence there is a need for the system to provide effective contents and suggest students with the appropriate contents. Some of the sample questions are listed below:

1. What types of digitally published content from the following are you familiar with?

2. Do you own any of the below mentioned gadgets that are used for electronic books?

3. Would you always prefer to get an electronic version of a textbook along with the purchase of a physical version of the same?

4. Have you listened to an Audio Book till date?

5. Will you fully convert to using digitally published text book for academic purposes immediately?

6. Have you till date ever subscribed to any course online?

7. If you take up any online course what will it be for?
8. Which form of online learning would you prefer to take up?

9. Have you had any kind of E-Classroom in your workplace/institution?

10. The study material given in such courses plays a very significant role in the longer run.

11. Do you refer to journals/ magazines as references to academic subjects?

12. Are you aware that if purchased online you can pay for per view for a journal and also purchase specific articles from a journal?

13. Have you subscribed to any of the sms or voice call updates to a provider, for study/research related purposes?

14. Do you think graphics and illustrations are necessary for mobile learning to be effective instead of sms and voice calls alone?

15. Do you think the cost of subscription for the sms is acceptable and feasible?

16. Do you like INSTANT ACCESS to any topic/ subject by any author/journal/magazine facilitated by digital technology?

\subsection{FOR TEACHERS/TUTORS ALONE}

17. Have you taught/Are you teaching any course online through the internet?

18. Have you been part of E-Classroom programs at any educational institution?

19. Were you given the required materials online by the website to start the classes?

20. 20 Did you take reference from any form of digitally published version of any textbook for it?

21. Specify the medium through which you refer to a journal

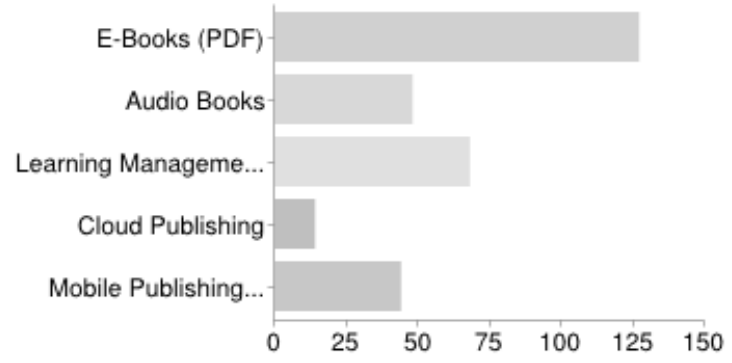

Fig 1: People learning materials by categories

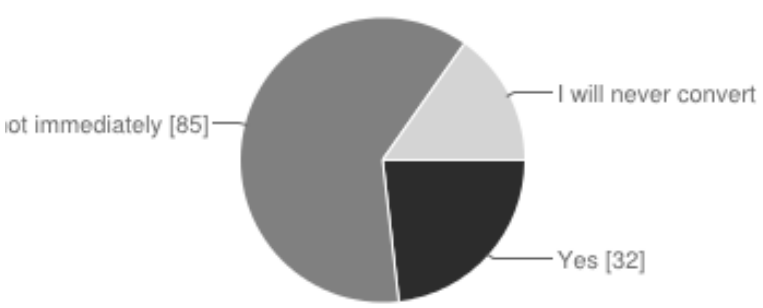

Fig 2: Response from people when asked whether they are willing to convert to adaptive systems 


\section{SYSTEM ARCHITECTURE \\ 4.1 AGENT BASED INTELLIGENT \\ TUTORING SYSTEM DEVELOPMENT}

Tropos is agent oriented modeling technique which is capable of capturing the different types of requirements. The phases of Tropos early requirements, late requirements, architecture design, detailed design and implementation. In our work, the ABITS is modeled using Tropos and the outcome of the modeling process had led us in defining the different types of agents and their roles. The phases of Tropos are described as follows:
Early Requirements: during this phase the relevant stakeholders in the system are identified, along with their respective roles

Late Requirements: the system-to-be is introduced as another actor and is related to stakeholder actors in terms of actor dependencies

Architectural Design: system actors are defined with further detail.

Detailed Design: In this phase the attributes of the agents and goals are modeled in detail.

Implementation: During this phase, the skeleton for the implementation phase is produced.

Table 1: Agents and its roles

\begin{tabular}{|c|c|c|c|}
\hline Si no. & Agent Name & Role & $\begin{array}{l}\text { Behavior/ AI techniques } \\
\text { applied }\end{array}$ \\
\hline 1 & Profile Analysis Agent & $\begin{array}{l}\text { Captures the Student's likeliness, capacity and } \\
\text { activity }\end{array}$ & Cyclic Behavior \\
\hline 2 & Preference Agent & $\begin{array}{l}\text { Suggest materials based on the students } \\
\text { preferences which is persisted }\end{array}$ & Cyclic Behavior \\
\hline 3 & Fuzzy suggestion Agent & $\begin{array}{l}\text { Suggest materials based on the Fuzzy C-means } \\
\text { clustering method }\end{array}$ & Clustering \\
\hline 4 & Mining Agent & $\begin{array}{l}\text { Suggest Materials based on the Association Rule } \\
\text { Mining }\end{array}$ & Association Rule Mining \\
\hline 5 & Exam Agent & Conducts Exams and update marks & One Shot Behavior \\
\hline 6 & Adaptive questions Agent & $\begin{array}{l}\text { Provides exam questions based on the } \\
\text { performance level of the students }\end{array}$ & One Shot Behavior \\
\hline 7 & User Interface Agent & $\begin{array}{l}\text { Persist the user interface attributes such as color, } \\
\text { position etc. and present the same interface } \\
\text { whenever the student logs in }\end{array}$ & Cyclic Behavior \\
\hline 8 & Tutor Agent & $\begin{array}{l}\text { Creation of course, editing course structure, } \\
\text { adding materials, rating materials }\end{array}$ & Cyclic Behavior \\
\hline 9 & Classification Agent & Classification of the course materials & Cyclic Behavior \\
\hline
\end{tabular}

Tropos conceptual models and diagrams are developed as instances of the following intentional and social concepts: actor, goal, dependencies, plan, resource, capability, and belief. In Tropos, the temporal constraints of the goals/tasks on the resources are not explicitly modeled and the security constraints of the resources are not discussed. Hence we extend the Tropos methodology and apply it to the requirements of the distributed tutoring system. Agent's role and the behavior is obtained by modeling this system using Tropos.

\subsection{AGENTS AND ROLES}

After the modelling phase, several agents and their roles have been identified. Such alagents are profile analysis agent, preference agent, fuzzy suggestion agent, mining agent, exam agent, adaptive questions agent, user interface agent, tutor agent, classification agent. The profile analysis agent and the learner agents are used to analysis the several characteristics of the learner, their likeliness, technical capabilities etc. The tutor agent performs the role of creating the course, announcement to students, analysis of student's path of learning and evaluating the learning process etc. The classification agent performs resource classification based on the hierarchical tree structure where the resources are represented in the tree like structure based on different courses. The student clustering agent helps to achieve the collaborative learning where similar learners are identified and they are allowed to communicate with each other.

The learner agents have three sub-types of agents. The evaluation agents perform all tests, including pre-learning tests and post-learning tests. Based on the evaluation results, the path planning agents analyze the learning profile and propose the course learning path. The problem mitigation agents have the responsibilities of learning problem analysis and assisting the learners to resolve the problems. The instructor agents can be course management agents or portfolio analysis agents. The course management agents assist the teachers to construct, arranges, and adjusts the course content. 


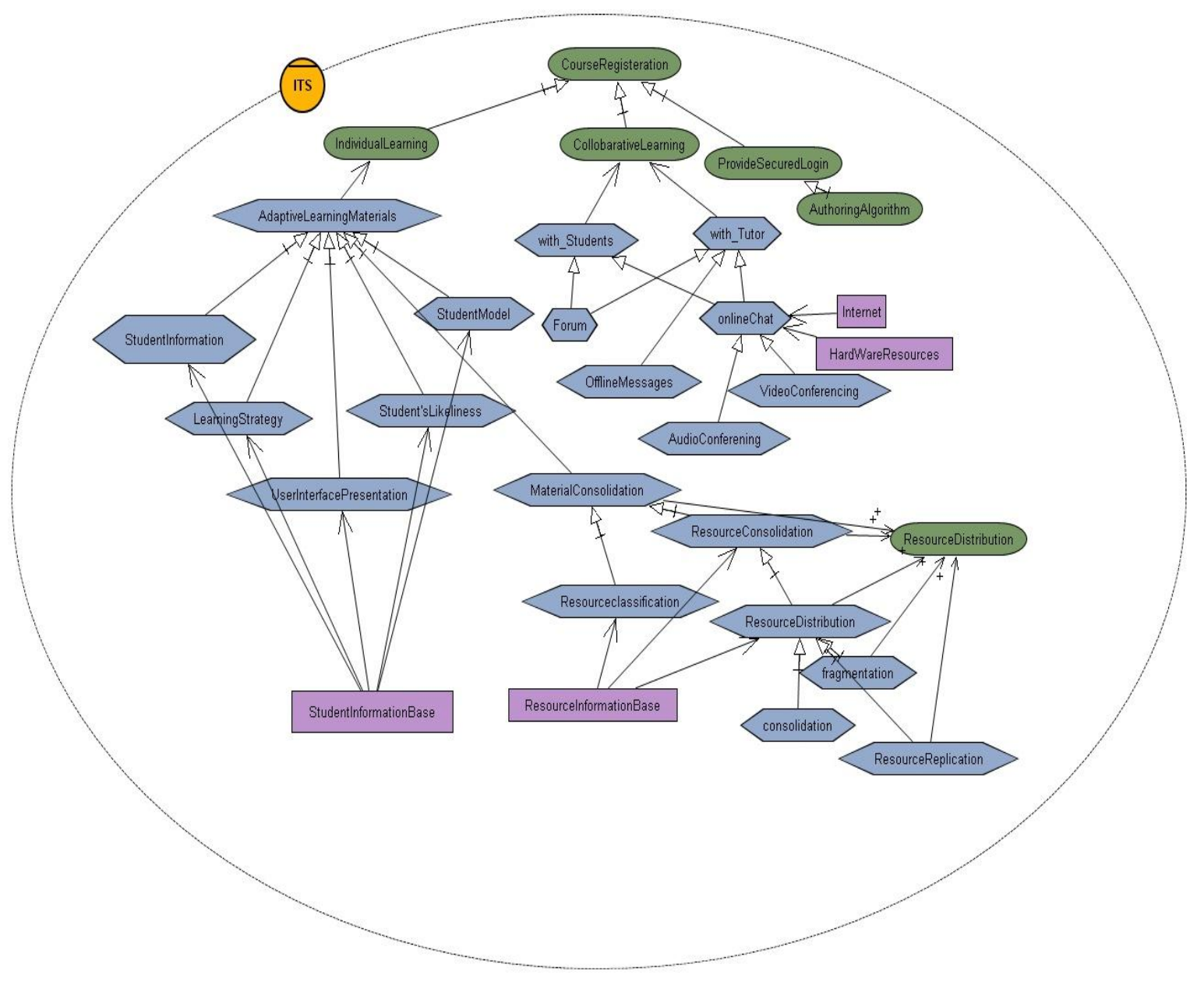

Fig 3: Agent based Intelligent Tutoring System Modeled using Tropos

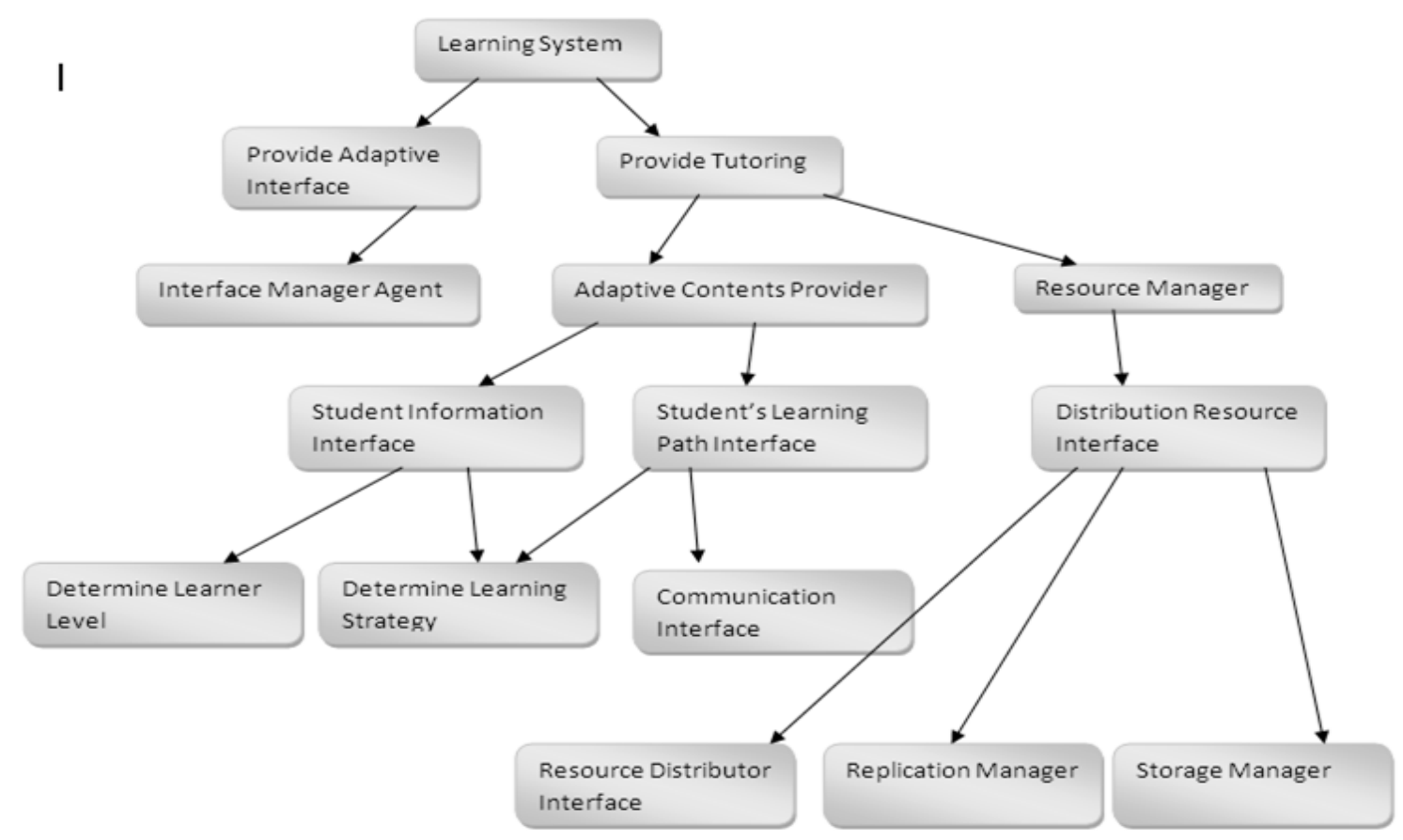

Fig 4: Architecture diagram for the Tutoring System 


\section{ADAPTIVE MATERIALS SUGGESTION}

The students are allowed to write three tests: pre-test, posttest, course completion tests. Based on the evaluation of these test results students are clustered using the FCM clustering agent and these agents suggest to the tutor agents.

During the course the students likeliness are captured and from the student's log file the association rule mining is applied and the students are given with the suitable contents.

The students are not allowed to search the entire contents of the course; instead they are allowed only to learn the contents in the specific classification of the course. This gives a clear way of learning from materials which are most relevant.

In our system, we construct a tree like structure for the representation of the course contents. Whenever the student is in particular level of course, only the contents which belong to the corresponding are only presented to the user. The resources can be classified into html, video, audio, flash or combination of those types. These contents have to be delivered adaptively to the user accordingly to the user's likeliness. The user's activity has to be monitored and in accordance to the user the adaptive user-interface is delivered by the system

In our work the adaptive materials are provided in three ways:

- $\quad$ By Fuzzy C-means clustering

- Association Rule Mining

- Materials by individual preferences

\subsection{ADAPTATIVE MATERIALS BY PREFERENCE}

The preference is persisted when the user signup in our system. The preference may be video, audio, ppt and text oriented materials. These preferences are persisted by the preference agent and retrieved whenever the student logs in to the system. The user would be asked to give the preference initially and whenever the user can change the preference.
Based on the preference and the materials available in the current title, the materials are presented to the student. In Figure X. the student's preference is video and he belongs to the title JVM, hence the video materials from the JVM are suggested to the student in the related contents by preference area.

\subsection{ADAPTIVE MATERIALS BY FUZZY C-MEANS CLUSTERING}

Fuzzy C- means is a method of clustering which allows one piece of data to belong to two or more clusters. It is based on the optimization of objective function. By iteratively updating the cluster centres and membership grades for each data point, Fuzzy $\mathrm{C}$ means moves the cluster centres to the right location within the dataset. Fuzzy C-means is a clustering algorithm that used membership degree to determine each data point belongs to a certain cluster. FCM divided the $n$ vectors $x_{i}(i=$ $1,2, \ldots, n$ ) into $\mathrm{c}$ fuzzy group, and computing the cluster centre of each group, making value function of non-similarity index to achieve the minimum.

FCM algorithm making each of the give data points with values between 0,1 membership to determine its degree of belonging to various groups through fuzzy partition. And to suit the introduction of fuzzy partition, the membership matrix ' $U$ ' allowed the element value between 0,1 . The above algorithm can also initialize cluster centre firstly, and run the iterative process after. The algorithm does not guarantee an optimal solution to the convergence, so its performance depends on the initial cluster centres. Therefore, another fast algorithm can be used to determine the initial cluster centres, or start the algorithm with different initial clusters centre every time, running FCM repeatedly.

Using the fuzzy clustering method the different types of students are identified and the different types of course contents are presented to the user according to their position in the cluster. Students are clustered based on the examination pre-test and post-test results. In the Figure $\mathrm{X}$. the suggested materials by fuzzy c-means clustering are shown to the user.

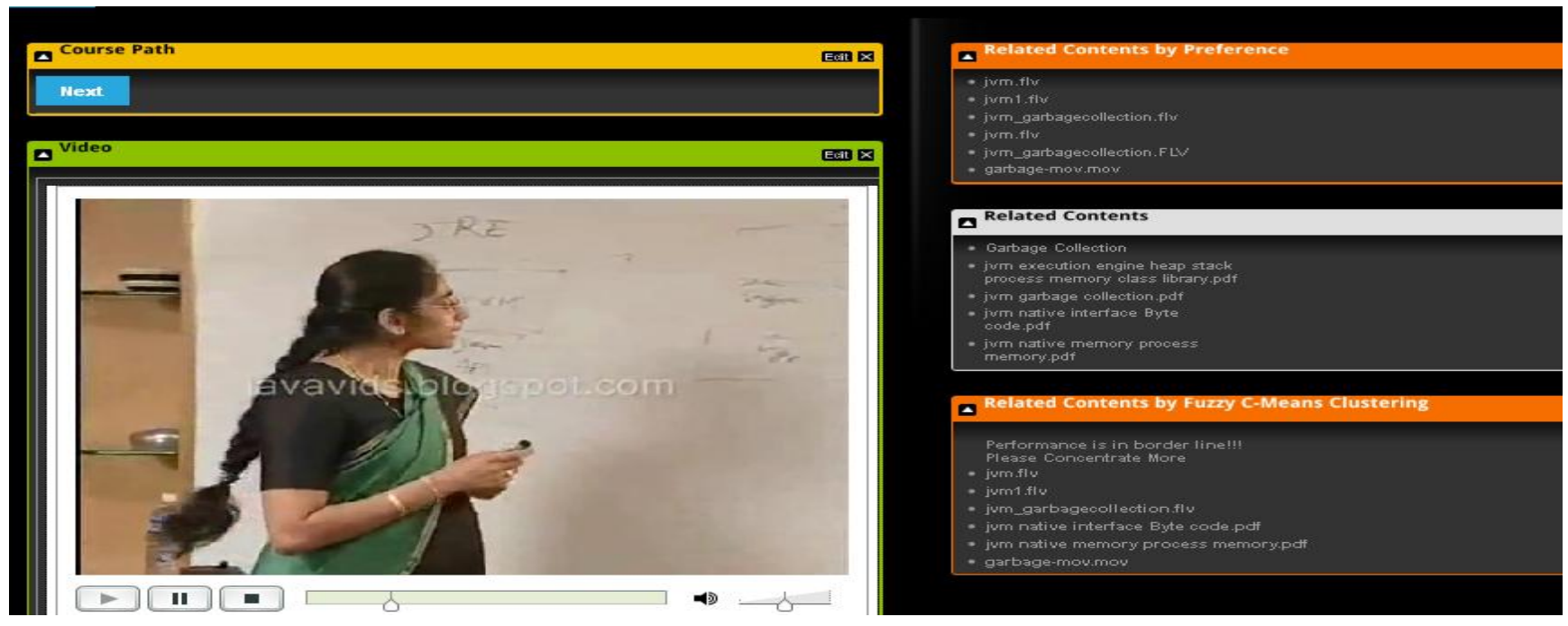

Fig 5: ABITS suggesting materials by preference and Fuzzy C-means Clustering 


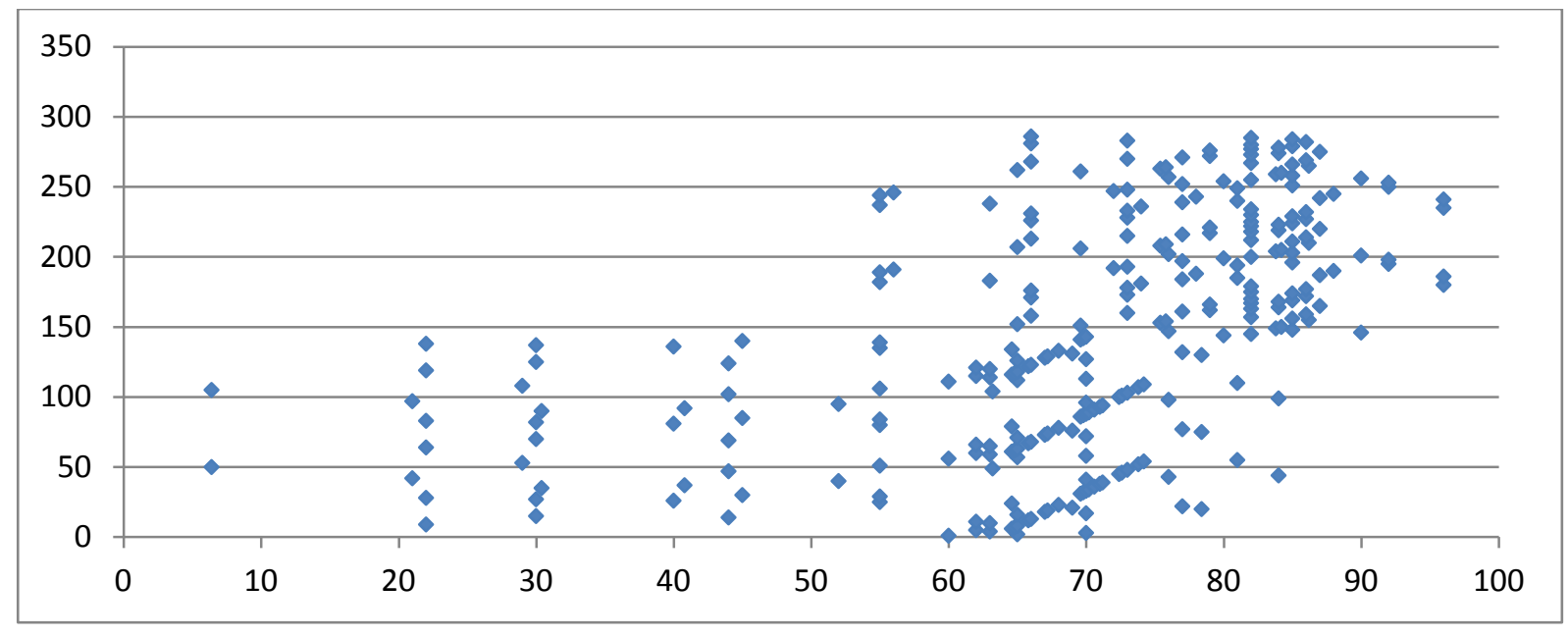

Fig 6: FCM Clustering with cluster centres as 25, 42 and 75

\subsection{APRIORI ALGORITHM - ASSOCIATION RULE MINING}

In this work, we have different types of course materials namely: video, audio, ppt, pdf and text. Whenever a student learns from a ppt, profile analysis agent stores this information in the database. Student learns java from different types of materials and this information is persisted. The next button in the user interface would suggest the materials based on the association rule mining technique.

For example consider a sequence: video->audio->video->ppt$>$ ppt->video->audio. From the entire student's data, the association rule is applied and the most viewed sequence is mined and from the most viewed sequence the students are suggested with the appropriate materials which belong to current title of the course.

\subsection{ADAPTIVE USER INTERFACE}

Adaptive user interface includes adaptive positioning of the contents, personalized attributes of the elements in the interface such as element, size. The User interface agent would persist the attribute values and whenever the user logs into the system, the elements are presented in the requested colour and position of those elements.

\subsection{EVALUATION OF PERFORMANCE OF STUDENTS}

The performance of the students is evaluated and the results will be plotted. The comparative analysis of the performance will be evaluated using the feedback and also by student's performance.
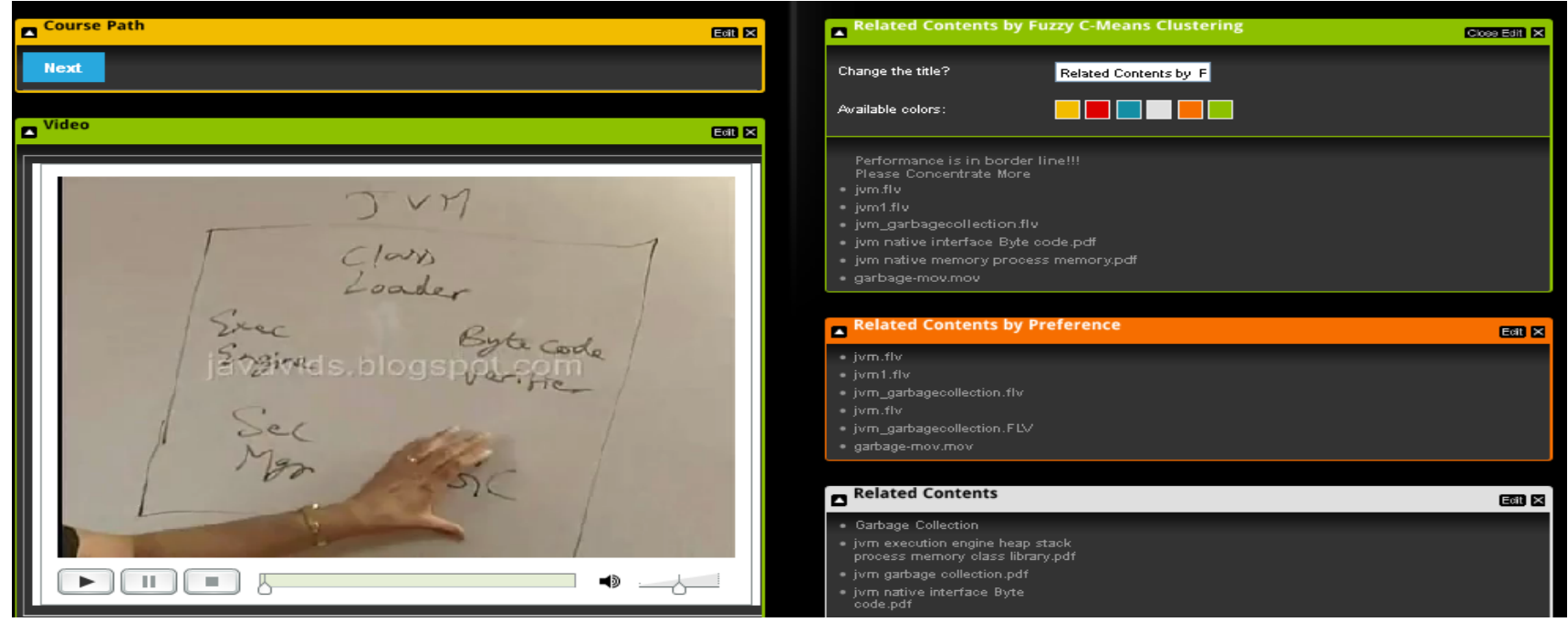

Fig 7: Interface depicting that the user can change the colour of each element 


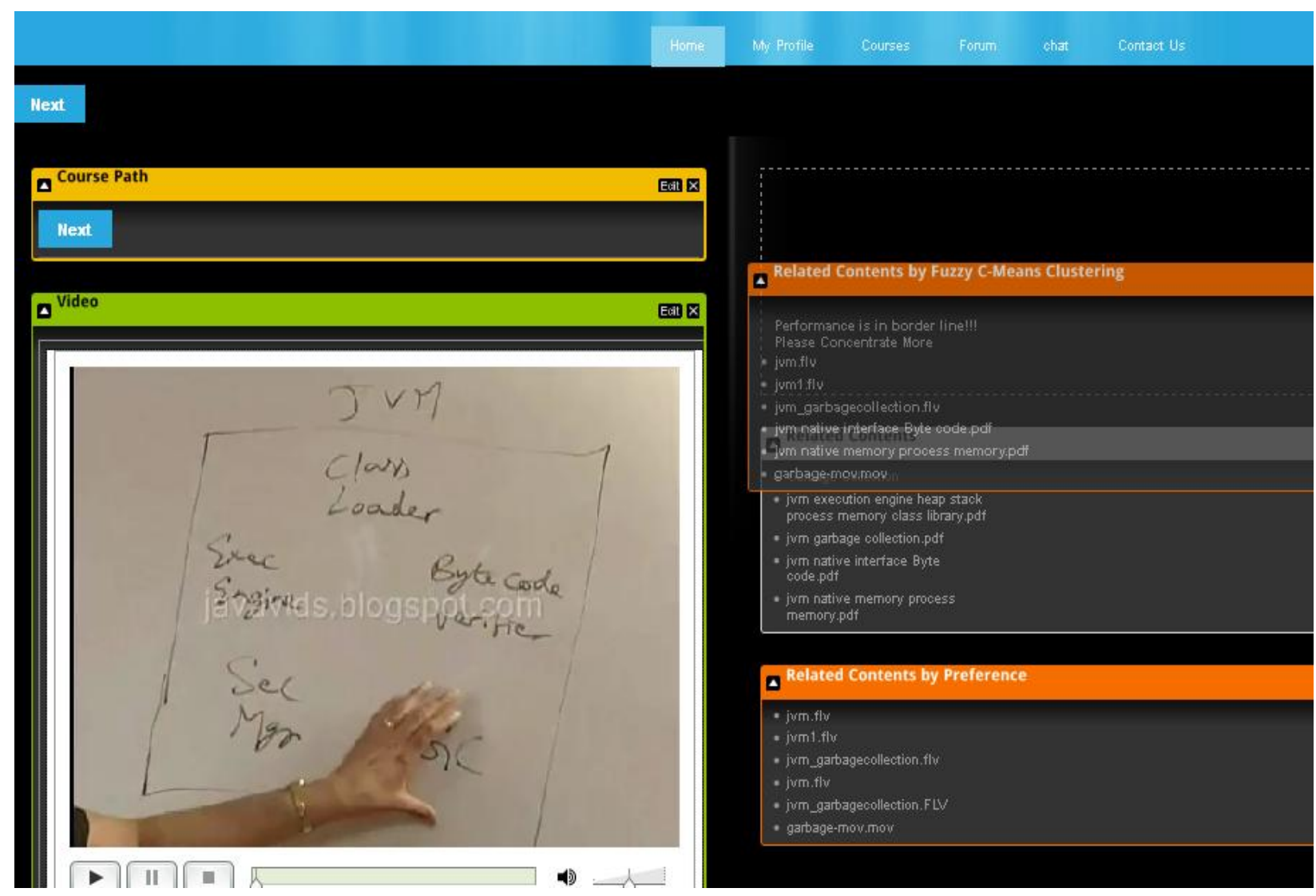

Fig 8: User Interface depicting that the student can place the contents anywhere in the screen

\section{EXPERIMENTAL RESULTS}

The student's results are analyzed with the pre-test and the post-test marks. Feedback from the students about the adaptiveness presented user is tabulated. Questions from 1 to 5 are related to the adaptive user interface presented to the user. Questions from 6 to 8 are related to the adaptive contents which are provided to the user by clustering and association mining techniques. Based on the questions 9 and 10, system's performance is evaluated. Questions from 11 to 14 ask about the confidence level after the learning process.
1. Is relevant materials presented to you?

2. Are you annoyed by any other user interface presented to you?

3. Is the user interface capable of modifications?

4. How would you rate this user interface?

5. Do you feel that this user interface presented to you is different from your friend?

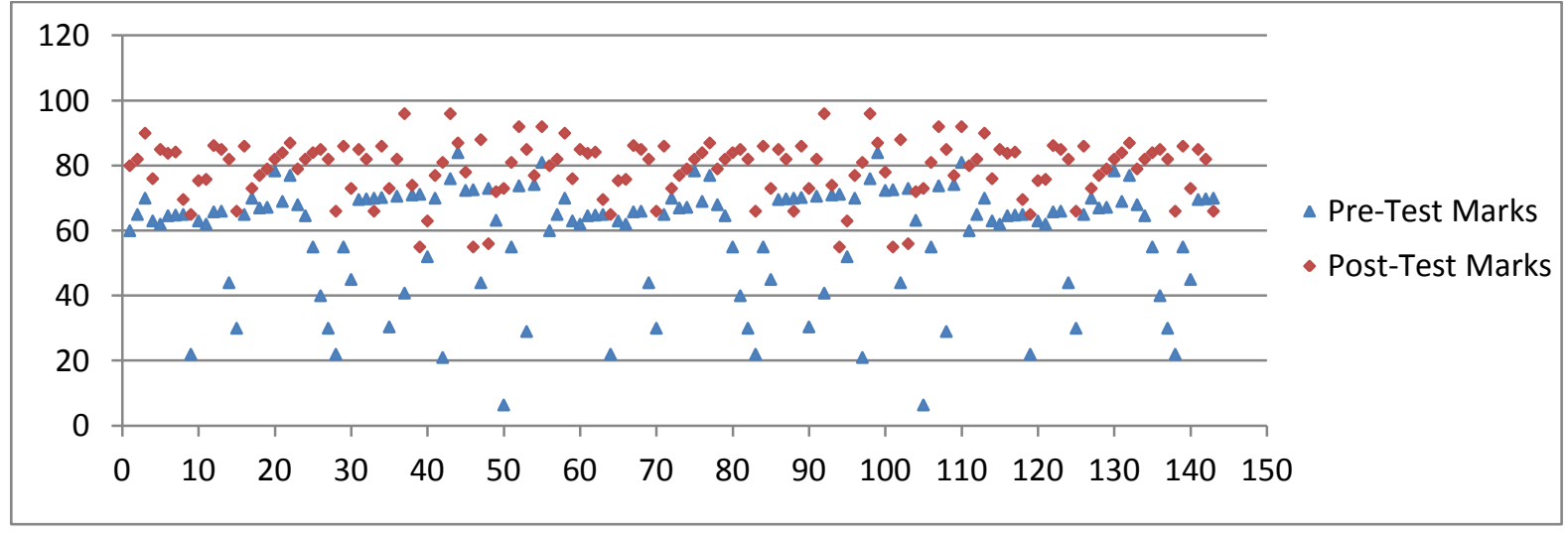

Fig 9: Comparative analysis of Pre-Test and Post-Test Marks 
6. Are you provided with the same contents as your friends' contents?

7. How would you rate the next button in the system?

8. Will the next button provides you guidance in navigating from one page to another?

9. How fast is the video materials are loaded?

10. Can the system able to deliver the contents in less time?
11. Are you annoyed for the contents to get loaded on the screen?

12. Does this system help you to learn the java programming?

13. Are you capable of developing any java based system?

14. How confident are you in java after completing this course?

Table 2. Contents and adaptive components in the system

\begin{tabular}{|l|l|l|}
\hline No. & Component & Description \\
\hline 1 & Pretest & $\begin{array}{l}\text { Test to assess the students initial } \\
\text { knowledge in Java }\end{array}$ \\
\hline 2 & Course Structure & List of course titles \\
\hline 3 & User Interface & $\begin{array}{l}\text { Adaptive user interface provided to the } \\
\text { students }\end{array}$ \\
\hline 4 & Materials & List of learning objects \\
\hline 5 & Suggested Materials & Materials suggested by the tutoring system \\
\hline 6 & Video Contents & $\begin{array}{l}\text { Video contents which is delivered to the } \\
\text { learner }\end{array}$ \\
\hline 7 & Posttest & Test to assess the students \\
\hline 8 & Interaction & Interaction with the system and the student \\
\hline 9 & Course Continuation & $\begin{array}{l}\text { Whenever the students logs into the } \\
\text { system, students can continue learning } \\
\text { where he logged off }\end{array}$ \\
\hline
\end{tabular}

Table 3. Distribution of the feedback results

\begin{tabular}{|c|c|c|c|c|}
\hline \multirow[t]{2}{*}{ Items } & $\begin{array}{l}\text { CS } \\
\text { Student }\end{array}$ & & \multicolumn{2}{|c|}{ Non-CS Students } \\
\hline & $\mathrm{M}$ & SD & $\mathrm{M}$ & SD \\
\hline It has high quality contents & 4.138 & 0.204 & 3.912 & 0.744 \\
\hline Provides adaptive contents & 4.227 & 0.103 & 4.445 & 0.211 \\
\hline Provides adaptive interface & 3.654 & 0.151 & 4.258 & 0.155 \\
\hline It enhances my programming skills & 4.774 & 0.207 & 3.985 & 0.201 \\
\hline It promotes self-learning & 3.921 & 0.704 & 3.485 & 0.115 \\
\hline General satisfaction level & 4.462 & 0.313 & 4.344 & 0.134 \\
\hline Confidence level after completion of course & 3.817 & 0.116 & 2.144 & 0.546 \\
\hline
\end{tabular}




\section{CONCLUSION}

This work starts from the requirement elicitation of the agent oriented systems and modeled using Tropos methodology with a real time extensive survey from the student community. Based on the modeling the agents and their goals are derived to develop the stable agent oriented system. In our system, students are provided with the adaptive materials using fuzzy c-means algorithm, association rule mining and preference. Adaptive user interface is also provided to the students which would encourage and motivate students to learn more contents. Finally, the adaptive examination is provided with the adaptive questions and the results are evaluated. From the pretest and posttest results, we can incur that the students programming capability has been increased. We also got feedback from students, which incurs that there is a definite positive feedback towards the system which also increases the satisfaction level and the confidence level after completing the course.

\section{REFERENCES}

[1] Brown, I. (1998). The effect of WWW document structure on students' information retrieval. Journal of Interactive Media in Education, 98(12), 1-18.

[2] Graf, S., \& Kinshuk, T.-C. L. (2010). Analysis of learners' navigational behaviour and their learning styles in an online course. Journal of Computer Assisted Learning, 26(2), 116-131.

[3] Graf, S. (2007). Adaptivity in learning management systems focusing on learning styles. Ph.D. dissertation, Vienna, Austria: University of Technology.

[4] Stash, N. (2007). Incorporating Cognitive/Learning Styles in a General-Purpose Adaptive Hypermedia System. Ph.D. dissertation, Eindhoven: Technische Universiteit, Eindhoven, Netherlands.

[5] Ghazarian, A., \& Noorhosseini, S. M. (2010). Automatic detection of users' skill levels using high-frequency user interface events. User Modeling and User-Adapted Interaction, 20(2), 109-146.

[6] Bruce M. McLaren a, Krista E. DeLeeuw. (2011). Polite web-based intelligent tutors: Can they improve learning in classrooms?. Computers \& Education, 56, 574 -584

[7] Monova-Zheleva, M. (2005). Adaptive learning in Webbased educational environments. Cybernetics and Information Technologies, 5 (1), 44-55.

[8] Rosmalen, P., Vogten, H., Van Es, R., Passier, H., Poelmans, P., \& Koper, K. (2006). Authoring a full life cycle model in standards-based adaptive e-learning. Educational Technology \& Society, 9 (1), 72-83.

[9] Damjanovic, V., Kravcik, M. \& Devedzic, V. (2005). An approach to the realization of personalized adaptation by using eq agent system. In Paper presented at workshop on personalization on the semantic Web: Held in conjunction with the 10th international conference on user modeling (UM’05), 24-30 July, Edinburgh, UK.

[10] Mahkameh Yaghmaie, Ardeshir Bahreininejad. (2011). A context-aware adaptive learning system using agents. Expert Systems with Applications, 38 (2011), 3280-3286

[11] Yanghee Kim, Quan Wei. (2011). The impact of learn er attributes and learner choice in an agent-based environment. Comp uters \& Education 56 (2011) 505 514.

[12] Shengnan $\mathrm{Ke}$, Xin $\mathrm{Lu}$ (2010). Study on Intelligent Tutoring System Based on Multi-Agents. In proc. of Sixth International Conference on Natural Computation, pp. 2948-2952

[13] R. Aguilar, V.Munoz, et. al. Fuzzy and Multi-Agent Instructional Planner for an Intelligent Tutorial System. Applied Soft Computing 11 pp. 2142-2150

[14] Keeley Crockett, Annabel Latham. et. al. (2011). On Predicting Learning Styles in Conversational Intelligent Tutoring Systems using Fuzzy Classification Trees. In proc. International Conference on Fuzzy Systems ,June 27-30, pp. 2482-2482

[15] Elena Verdú, María J. Verdú, et. al. A genetic fuzzy expert system for automatic question classification

[16] in a competitive learning environment, Expert Systems with Applications 39 (2012) 7471-7478

[17] Volha Bryl, Paola Mello, et al, "B-Tropos Agentoriented requirements engineering meets computational logic for declarative business process modeling and verification", in proc 8th Workshop on Computational Logic in Multi-Agent Systems (CLIMA-VIII), 2007.

[18] Siena, A., Mylopoulos, J., et al, "Designing LawCompliant Software Requirements", in proc. ER 2009.

[19] Marco Montali, Paolo Torroni, et al, "Engineering and Verifying Agent-Oriented Requirements augmented by Business Constraints with B-Tropos", in Auton Agent Multi-Agent Systems, vol 23, pp. 193-223, 2011 